\title{
EPIDEMIOLOGIC, ECOLOGIC AND MICROBIO- LOGIC STUDIES OF TULAREMIA IN BULGARIA FOR 1997-2006 PERIOD
}

\author{
Milena Karcheva, Victoria Doycheva*, Todorka Dimitrova*, Krastu Marinov** \\ Department of Infectious diseases, Epidemiology, Parasitology and Tropical \\ Medicine, Medical University, Pleven, Bulgaria \\ * Department of Epidemiology, Medical University, Sofia, Bulgaria \\ ** Microbiologic Laboratory, Military Medical Academy, Sofia, Bulgaria
}

\section{SUMMARY:}

Tularemia is a zoonotic, acute, infectious disease caused by the bacterium Francisella tularensis. It is a major problem on the Europe and Balkan Peninsula. In Western Bulgaria two new foci originated during the last 10 years. Aims: To study epidemiology, ecology, nosogeography, conflict and prevention of tularemia that originated during 1997 - 2006 in Bulgaria. Materials and methods: Epidemiological method, Ecological method, Microbiological method, Clinical method, Statistical method. Results: During the last 10 years two endemic foci originated in the physic - geographic regions: Nishav - Borel (near Slivnitsa) and Kraishten (near Pernik) with 40 permanent noso - areas. The study determined that in the Sofia region the number of diseased with tularemia during 1997-2006 is 111 with morbidity $37,16 \%$ ooo, and in Pernik region the number of the diseased during the same period is 137 with morbidity $80,38 \%$ ooo. Conclusion: In the complex studies of both regions where tularemia developed we found out that the parasite system functioned with its components: a large number of sources and vectors, favourable climatic and geographic conditions and considerable number of factors of the ecologic socio - ecosystem.

Key words: Tularemia, Incidence, Epidemiological investigation

\section{INTRODUCTION}

The epidemiologic result of the century - old tularemia history shows that the disease continues to spread pandemically. In Europe only during the last 70 - 80 years tularemia was found in 20 countries. The incidence (cases per 100000 population) in that countries is: Finland $(7,64)$, Sweden (1,91), Hungary $(0,2)$, Czech Republic $(0,53)$, Russian Federation $(0,08)$, Bulgaria $(0,04)$, Serbia $(0,07)$. The natural as well as the social and ecologic systems guarantee the preservation of the microbial species by means of the epizootic and epidemic processes.

\section{AIMS}

To study epidemiology, ecology, nosogeography, conflict and prevention of tularemia that originated during 1997 - 2006 in Bulgaria. In relation to that objective we set the following tasks: to study the physic - geographic and social - ecologic peculiarities of the affected areas; the development of tularemia infection in Western Bulgaria during 1997-2006; epidemiologic study of all patients with tularemia who became sick in the natural focus; study of control measures efficacy in the noso - areas.

\section{MATERIALS AND METHODS}

Data from the National Statistics Centre have been used. During 1997 - 2006248 patients with tularemia were studied from all noso - areas. Laboratory results from microbiological researches carried out in the microbiological laboratories of the National Centre of Infectious and Parasitic Diseases (NCIPD) and the Military Medical Academy (MMA) have been used. Demographic and infrastructural data from the municipalities of both regions have been used. The following methods have been applied: Epidemiological method (epidemiological investigation, epidemiological analysis); Ecological method (determining the fauna species in the natural focus, determining the physic and geographic characteristics of the affected areas, cartographic method); Microbiological method (cultural methods, serologic methods, molecular and genetic methods: PCR); Clinical method; Statistical method.

\section{RESULTS AND DISCUSSIONS}

The total number of diseased and tularemia morbidity in the country during 1997-2006 are 288 and 3,61\%ooo respectively. In the areas of Western Bulgaria these indices are 248 и $145,87 \%$ ooo respectively. The highest degree of morbidity was registered in $1998(1,15 \%$ ooo $)$, and the lowest one in $2001(0,05 \%$ ooo $)$. Two endemic foci originated in the physic - geographic regions: Nishav - Borel (near Slivnitsa) and Kraishten (near Pernik) with 40 permanent noso - areas. 
The study determined that in the Sofia region the number of diseased with tularemia during 1997-2006 is 111 with morbidity $37,16 \%$ ooo, and in Pernik region the number of the diseased during the same period is 137 with morbidity $80,38 \%$ ooo. In the complex studies of both regions where tularemia developed we found out that the parasite system functioned with its components: a large number of sources and vectors (Tabl.1), favourable climatic and geographic conditions and considerable number of factors of the ecologic socio - ecosystem.

An epidemic form of disease development was registered in three populated areas: village of Meshtitsa 57 diseased with morbidity $5523,25 \%$ ooo, village of Aldomirovtsi - 62 diseased with morbidity 4 585,79\%ooo and town of Slivnitsa - 29 diseased with morbidity 371,84 $\%$ ooo.

The infection usually occurs in the autumn - winter period (November - March). The largest number of diseased was registered in February - 58 (23,39\%), and the smallest number was registered in June - $2(0,8 \%)$, (Fig.1). In both regions the tularemia diseased are predominantly in the villages $-187(75,4 \%)$. In the towns they are $61(24,6 \%)$. The age peculiarities show that most afected are the people in the following age groups: 30 - 39 (13,3\%), 40 - 49 (14,92\%), $50-59(16,13 \%)$ and above $60(20,56 \%)$.

The professional peculiarities of the diseased show that mainly hunters, farmers dealing with animal breeding and other agricultural activities get infected with tularemia. Certain people stayed in the endemic areas, however, they were diseased in Sofia (19) and Pernik (14).

On the grounds of these observations we concluded that the main way of infection transfer is the alimentary one with major factors food and water (positive result from water samples). In certain cases the process of infection is transmissive - due to ticks bites, especially in the summer when the ticks population is extremely active; and droplet way during mowing and hay - making. The death rate and lethality among all studied diseased is actually zero.

Serologic studies in a laboratory confirmed the diagnosis among the diseased. Titres of antibodies from 1:400 to 1: 25600 have been found. The largest number of diseased have titres 1:3200 - 30, 1: 6400 - 48 and 1: 12800 121. Clinical forms among the studied diseased with tularemia we showed on the Tabl.2.

\section{CONCLUSION.}

The epidemic starts all of a sudden, and develops gradually but continuously. It spreads in many populated areas (over 20) the territory being more than 4000 sq.m. It affects mainly farmers. The source of infection are mainly mouse - like rodents and rabbits. The isolated cultures of a tularemia microbe refer to biotype II - Holarctic, typical for the area where our country is located. The geographic and natural conditions as well as the biocenotic system in the area where the epidemic develops are favourable to keep the enzootic tularemia. From the clinical point of view the diseases are mainly oropharyngeal, however, there are also cases with a pulmonary form, as well as atypical and not so serious cases. The disease develops endemically, with a large number of sources and vectors, with a lot of factors and ways of development; it runs comparatively mild with a low percent of lethality; despite the applied classic methods of prevention the disease is described mainly as "non-controllable".

Tabl. 1. Reservoir of infection

\begin{tabular}{|l|l|}
\hline \multicolumn{1}{|c|}{ Animals - sources of the disease with } & \multicolumn{1}{c|}{ Vectors } \\
\hline 34 Rattus rattus, (black rat); & Fr. Tularensis have been isolated from the ticks of \\
6 Mus musculus, (house-mouse); & Ixodes Ricinus type \\
2 Apodemus agrarius (black-striped field-mouse); & and \\
1 Microtus arvalis, (common vole); & 2 strains of Dermacentor marginatus type. \\
6 Dead wild rabbits. & \\
\hline
\end{tabular}

Tabl. 2. Clinical forms

Clinical forms

\begin{tabular}{|lc|}
\hline \multicolumn{2}{|c|}{ Clinical forms } \\
\hline Oropharyngeal form & 225 diseased $(90,72 \%)$ \\
Oculoglandular form & 8 diseased $(3,2 \%)$ \\
Cutaneous - bubonic (ulceroglandular) one & 7 diseased $(2,8 \%)$ \\
Pneumonic form & 7 diseased $(2,8 \%)$ \\
One case, described by Prof. I. Dikov is determined as a typhoid form & \\
\hline
\end{tabular}




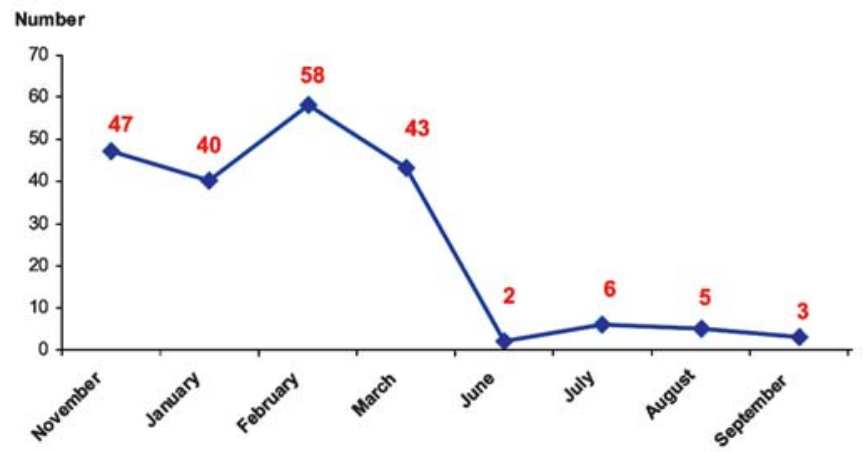

Fig. 1. Monthly distribution of the tularemia diseased

\section{REFERENCES:}

1. Brantsaeter, AB., et al, Tularemia outbreak in northern Norway. Euro Surveill. 12 (13): pii $=3165 ; 2007$

2. Cerny, ZD., Changes of epidemiology and the clinical picture of Tularemia in Southern Moravia (the Gzech Republic) during the period 1936-1999, Eur. J. Epidemiol, 17 (7), 637-42; 2001

3. Center for Disease Control and Prevention, Division of Public Health Surveillance and Informatics. Tularemia (Francisella tularensis). 1999 case definition. [cited20Feb2000]. Available from:http://www.cdc.gov/epo/dphsi/ casedef/tularemia_current.htm

4. Kantardjiev, T., et al, Tularemia Outbreak, Bulgaria, 1997-2005, EID, Vol. 12, № 4, April, 678-680; 2006
5. Kantardjiev, T., I. Ivanov, Study of Bulgarian Tularemia Outbreaks: Diagnosis and Epidemiology, Medical Aspects of Chemical and Biological Terrorism, Sofia, Publishing House of the Union of Scientists in Bulgarian, 125-131; 2004

6. Martin, C., et al, Autbreak of tularemia in Castilla and Leon, Spain, Eurosurveillance, Vol. 12, Issue 11; 2007

7. Morner, T., The ecology of tularemia. Rev. Sci. Tech. Off. Inf. Epiz. 11; 11235-1130; 1992

8. Nibylski, M., et al, Characterization of an endosymbiont infecting wood ticks, Dermacentor andersoni, as a member of the genus Francisella. Appl. Environ. Microbiol, 63, 3933-3940; 1997

9. Parola, P., D. Raoult, Ticks and tickborne bacterial diseases in humans: an emerging infectious threat. Clin. Infect. Dis. 32:897-28; 2001

10. Pearson, D.P. Tularemia. In\& Palmer S.R., Lord Soulsby, Simpson DIH, editors. Zoonoses: biology, clinical practice and public health control. Oxford: Oxford University Press: p. 267-80; 1998

11. Perez-Castrillon, J., et al, Tularemia epidemic in northwestern Spain: Clinical description and theurapeutic response; Clin. Infect. Dis., 33:573-576; 2001

12. Reintjes, R., et al, Tularemia outbreak investigation in Kosovo: case control and environmental studies. Emerging Inf. Diseases, vol. 8, № 1, January, 69-73; 2002

\section{Address for correspondence:}

Milena Karcheva, MD;

Department of Infectious diseases, Epidemiology, Parasitology and Tropical

Medicine, Medical University - Pleven

1, St. Kliment Ohridski, Str.; 5800 Pleven, Bulgaria;

e-mail: milena_karcheva@abv.bg 